\title{
Selective Enhancement of Synaptic Inhibition by Hypocretin (Orexin) in Rat Vagal Motor Neurons: Implications for Autonomic Regulation
}

\author{
Scott F. Davis, ${ }^{1}$ Kevin W. Williams, ${ }^{2}$ Weiye Xu, ${ }^{1}$ Nicholas R. Glatzer, ${ }^{1}$ and Bret N. Smith ${ }^{1,2,3}$ \\ ${ }^{1}$ Department of Cell and Molecular Biology, ${ }^{2}$ Tulane Neuroscience Training Program, and ${ }^{3}$ Department of Neurosurgery, Tulane University, New Orleans, \\ Louisiana 70118
}

\begin{abstract}
The hypocretins (orexins) are hypothalamic neuropeptides implicated in feeding, arousal, and autonomic regulation. These studies were designed to determine the actions of hypocretin peptides on synaptic transmission in the dorsal motor nucleus of the vagus nerve (DMV). Whole-cell patch-clamp recordings were made from DMV neurons in transverse slices of rat brainstem. Some of the neurons were identified as gastric-related by retrograde labeling after inoculation of the stomach wall with pseudorabies virus 152, a viral label that reports enhanced green fluorescent protein. Consistent with previous findings, hypocretins caused an inward current (6-68 pA) in most neurons at holding potentials near rest. In addition, the frequency of spontaneous IPSCs was increased in a concentration-related manner (up to 477\%), with little change in EPSCs. This effect was preserved in the presence of tetrodotoxin, suggesting a presynaptic site of action. Hypocretins increased the amplitude of IPSCs evoked by electrical stimulation of the nucleus tractus solitarius (NTS) but not evoked EPSCs. Hypocretin-induced increases in the frequency of IPSCs evoked by photoactivation of caged glutamate within the NTS were also observed. Identical effects of the peptides were observed in identified gastric-related and unlabeled DMV neurons. In contrast to some previous studies, which have reported primarily excitatory actions of the hypocretins in many regions of the CNS, these data support a role for hypocretin in preferentially enhancing synaptic inhibition, including inhibitory inputs arising from neurons in the NTS. These findings indicate that the hypocretins can modulate and coordinate visceral autonomic output by acting directly on central vagal circuits.
\end{abstract}

Key words: parasympathetic; viscerosensory; pseudorabies; brainstem; feeding; arousal

\section{Introduction}

The hypocretins, also called orexins, are neuropeptides produced in and near the lateral hypothalamus (de Lecea et al., 1998; Sakurai et al., 1998). Hypocretin-containing axons are widely distributed in the CNS, particularly in areas involved in feeding and autonomic regulation (de Lecea et al., 1998; Peyron et al., 1998; Date et al., 1999; Harrison et al., 1999). Correspondingly, central hypocretin administration increases feeding in rats (Sakurai et al., 1998), in part by delaying behavioral satiety (Rodgers et al., 2000), and stimulates cardiovascular and sympathetic function (Shirasaka et al., 1999; Chen et al., 2000). Involvement of hypocretin in sleep and wakefulness is also apparent (Hagan et al., 1999; Lin et al., 1999; Siegel, 1999; Gerashchenko et al., 2001), and a role for the peptides has been proposed in coordinating autonomic tone with arousal (Mieda and Yanagisawa, 2002; Sutcliffe and de Lecea, 2002).

A principal brainstem area controlling autonomic function is the dorsal vagal complex (DVC). Central processes of sensory vagal neurons serving the gastrointestinal viscera synapse with second order neurons in the caudal portions of the medial nu-

Received Aug. 22, 2002; revised Jan. 24, 2003; accepted Feb. 18, 2003.

The research for this project was supported by National Institutes of Health Grant DK56132, National Science Foundation Grant IBN-0080322, and American Heart Association Grant 0030284N. We thank Dr. L. W. Enquist for the generous gift of the PRV152, Drs. W. Halford and C. Wilcox for assistance with handling the virus, Dr. A. N. van den Pol for supplying hypocretin 2 antibody, and Dr. J. G. Tasker for comments on this manuscript.

Correspondence should be addressed to Dr. Bret N. Smith, Department of Cell and Molecular Biology, 2000 Stern Hall, 6400 Freret Street, Tulane University, New Orleans, LA 70118. E-mail: BNSmith@Tulane.edu.

Copyright $\odot 2003$ Society for Neuroscience $\quad 0270-6474 / 03 / 233844-11 \$ 15.00 / 0$ cleus tractus solitarius (NTS). Corresponding parasympathetic visceral motor output originates in the dorsal motor nucleus of the vagus nerve (DMV). Visceral afferent stimuli activate NTS neurons, some of which make glutamatergic and GABAergic synaptic connections with neurons in the DMV, forming a local reflex circuit (Travagli et al., 1991). Hypothalamic projections, including hypocretin fibers, innervate the DVC, implying that descending inputs can combine with local circuits to regulate autonomic output (Peyron et al., 1998; Date et al., 1999). Supporting a functional role for hypocretin in the DVC, a vagally mediated component to hypocretin-induced feeding has been demonstrated previously (Takahashi et al., 1999). However, it is not clear that hypocretins act within the DVC to affect feeding (Dube et al., 1999), and the ability of hypocretin to modulate gastric activity by acting in the nucleus may be specific to levels of the DMV rostral to the obex (Dube et al., 1999; Krowicki et al., 2002).

Effects of hypocretin at the cellular level have been described in several CNS regions and are mostly excitatory. Hypocretin applied to neurons in vitro enhances synaptic transmission in some hypothalamic and locus coeruleus neurons (van den Pol et al., 1998; Horvath et al., 1999). A membrane depolarization is typically observed in several brainstem areas (Brown et al., 2001; Burlet et al., 2002; Yang and Ferguson, 2002), including the NTS (Smith et al., 2002) and DMV (Hwang et al., 2001). Although coordinated autonomic output is closely regulated by the synaptic input to DMV neurons (Travagli et al., 1991; Browning and Travagli, 1999; Browning et al., 2002), nothing is currently 
known about the effects of hypocretin on synaptic activity in the nucleus.

The DMV plays a critical role in regulating digestion and other autonomic functions, and synaptic inputs are important regulators of DMV activity. These experiments were designed to test the hypothesis that, in addition to its depolarizing effects, hypocretin modulates synaptic connections in the DMV, including inputs to gastric-related neurons.

\section{Materials and Methods}

Prelabeling of gastric-related neurons with pseudorabies virus 152. Male Sprague Dawley rats ( Harlan Sprague Dawley, Indianapolis, IN), 4-8 weeks of age, were housed under a standard $12 \mathrm{hr}$ light/dark cycle with food and water provided ad libitum. All animals were treated and cared for in accordance with the rules of the Tulane University Animal Care and Use Committee and National Institutes of Health guidelines. For some experiments, a retrogradely transported viral vector that reports enhanced green fluorescent protein (EGFP) was used to identify gastricrelated neurons (Jons and Mettenleiter, 1997; Smith et al., 2000; Pickard et al., 2002). Under sodium pentobarbital anesthesia (Nembutal, $50 \mathrm{mg} /$ kg, i.p.; Abbott Labs, Chicago, IL), a laparotomy was performed, and the gastric musculature was injected with an attenuated (Bartha) strain of pseudorabies virus (PRV), constructed to express EGFP (PRV-152; generously supplied by Dr. L. W. Enquist, Princeton University, Princeton, $\mathrm{NJ})$. As described previously in detail for unlabeled PRV tracing studies (Card et al., 1990, 1993; Rinaman et al., 1993), three to five injections (1 $\mu l$ each) of PRV-152 at a titer of $1-2.4 \times 10^{8} \mathrm{pfu} / \mathrm{ml}$ were made into the gastric wall musculature on the ventral surface of the corpus using a $10 \mu \mathrm{l}$ Hamilton syringe (Hamilton, Reno, NV) fitted with a 26 ga needle. The needle was left in place for an additional $30 \mathrm{sec}$ at each site before removal. A fresh aliquot of PRV-152 was thawed for each injection from frozen stock. Animals were maintained in a biosafety level 2 laboratory for up to $96 \mathrm{hr}$ after injection in which they were allowed to recover. Food and water, monitored to ensure that they were consumed at a normal rate, were provided ad libitum.

On the basis of preliminary studies and previous reports of PRV neuronal infection stages (Card et al., 1993; Rinaman et al., 1993), labeling in the brainstem and other areas of the brain was examined at $60-75 \mathrm{hr}$ after infection. This time period resulted in labeling of neurons in the DMV sufficient to allow targeting of neurons for recording but is more than $1 \mathrm{~d}$ before the time at which electron microscopic studies indicated signs of membrane damage from the virus (Rinaman et al., 1993). Some animals were perfused transcardially with $4 \%$ paraformaldehyde in $0.15 \%$ sodium phosphate buffer, $\mathrm{pH}$ 7.4. The brains were removed and postfixed overnight at $4^{\circ} \mathrm{C}$ in paraformaldehyde, at which time they were rinsed in multiple washes of PBS, pH 7.2, equilibrated in 30\% sucrose in PBS, and sectioned at $30 \mu \mathrm{m}$ on the freezing stage of a sliding microtome. Sections were mounted on slides, air dried, and coverslipped in Vectashield to retard photobleaching (Vector Laboratories, Burlingame, CA). Images were captured with a Spot RT CCD camera (Diagnostic Instruments, Sterling Heights, MI) using an EGFP-shifted filter set (Chroma Technology, Brattleboro, VT) on a Leica DMLB microscope (Leica, Nussloch, Germany).

Slice preparation. Rats were deeply anesthetized with sodium pentobarbital (100 mg/kg, i.p.) or Halothane (Sigma, St. Louis, MO) inhalation and then decapitated while anesthetized. The brain was removed and blocked coronally rostral to the cerebellum on an ice-cold stand. The brainstem was then glued to a sectioning stage with cyanoacrylate-based adhesive. Transverse brainstem slices $(300-400 \mu \mathrm{m})$ containing the caudal vagal complex were made in $0-2^{\circ} \mathrm{C}$, oxygenated $\left(95 \% \mathrm{O}_{2}\right.$ or $\left.5 \% \mathrm{CO}_{2}\right)$ artificial CSF (ACSF) using a vibrating microtome (Vibratome Series 1000; Technical Products International, St. Louis, MO). The ACSF contained the following (in $\mathrm{mM}$ ): $124 \mathrm{NaCl}, 3 \mathrm{KCl}, 2 \mathrm{CaCl}_{2}, 1.3 \mathrm{MgCl}_{2}, 1.4$ $\mathrm{NaH}_{2} \mathrm{PO}_{4}, 26 \mathrm{NaHCO}_{3}, 11$ glucose, $\mathrm{pH} 7.3-7.4$, with an osmolarity of $290-315 \mathrm{mOsm} / \mathrm{kg}$. Slices were incubated for at least $1 \mathrm{hr}$ in $33-35^{\circ} \mathrm{C}$ oxygenated ACSF. In most cases, a single brain slice was then transferred to a submersion-style recording chamber on a fixed stage mounted under an upright (Olympus BX50WI; Olympus Immunochemicals, Melville,
NY) or an inverted (Nikon TE200; Nikon, Melville, NY) microscope and continuously perfused with ACSF. The ACSF used for recordings was identical to that used in the dissection.

Electrophysiological recording. Whole-cell patch-clamp recordings were obtained in the DMV using patch pipettes with open tip resistances of 3-5 M $\Omega$. Patch pipettes were filled with the following (in $\mathrm{mM}$ ): 130 $\mathrm{K}^{+}$-gluconate (or Cs ${ }^{+}$-gluconate), $1 \mathrm{NaCl}, 5 \mathrm{EGTA}, 10 \mathrm{HEPES}, 1 \mathrm{MgCl}_{2}$, $1 \mathrm{CaCl}_{2}, 3 \mathrm{KOH}$ (or $\mathrm{CsOH}$ ), 2-4 ATP; 0.2\% biocytin, pH 7.2-7.4. Pipettes were pulled from borosilicate glass capillaries of $0.45 \mathrm{~mm}$ wall thickness (Garner Glass, Claremont, CA). In most cases, neurons were targeted for recording under a $40 \times$ water-immersion objective (numerical aperture, 0.8) using infrared-differential interference contrast (IRDIC) optics. For recordings from EGFP-labeled DMV neurons (i.e., they were infected retrogradely from the stomach with PRV-152), initial visualization was made briefly under epifluorescence by using an FITC filter set. The epifluorescence illumination was then stopped and IR-DIC illumination was used to guide the recording pipette onto the cell for whole-cell analysis of synaptic currents. Recorded neurons were visualized, and their EGFP content was documented on-line using a Spot RT Slider CCD camera (Diagnostic Instruments).

Electrophysiological signals were recorded using either an Axopatch 200B or Axopatch 1D amplifier (Axon Instruments, Union City, CA). Signals were low-pass filtered at $2-5 \mathrm{kHz}$, digitized at $88 \mathrm{kHz}$ (Neurorecorder; Cygnus Technology, Delaware Water Gap, PA), and recorded on videotape and to a PC-style computer (Digidata 1320A; Axon Instruments). Data were captured using the pClamp program suite (Axon Instruments) and analyzed using pClamp programs or mini-analysis (Synaptosoft, Decatur, GA). Once in the whole-cell configuration, cells were initially held near the resting membrane potential for 5-10 min to allow equilibration of the cytoplasm and recording electrode solution. Seal resistances were typically 2-4G $\Omega$, and series resistance, measured from brief voltage steps $(5 \mathrm{mV}, 5 \mathrm{msec})$ applied through the recording pipette, was typically $<20 \mathrm{M} \Omega$ and monitored periodically during the recording. Recordings in which a $>20 \%$ change in series resistance was measured during drug application were excluded from the analysis. Input conductance was assessed by measuring the current at the end of brief voltage pulses of $5-10 \mathrm{mV}$ or by determining the linear slope conductance from a voltage ramp protocol, as described previously (Smith et al., 2002). Peptide-induced changes in holding current were assessed while the neuron was voltage clamped between -60 and $-80 \mathrm{mV}$. Resting membrane potential was determined by periodically monitoring the voltage at which no current was measured (i.e., removing voltage-clamp control of the neuron by switching to $I=0)$ during the recording. Electrical stimulation of the NTS $(300 \mu \mathrm{sec}, 0.1 \mathrm{~Hz})$ was performed using either a bipolar electrode made from a pair of Teflon-coated platinumiridium wires ( $75 \mu \mathrm{m}$ diameter, $\sim 100 \mu \mathrm{m}$ tip separation) or a concentric bipolar platinum-iridium electrode $(125 \mu \mathrm{m}$ diameter; Frederick Haer Company, Bowdoinham, ME). Stimulation intensity was adjusted so that PSCs were evoked after $>75 \%$ of the trials. For spontaneous PSCs (i.e., sEPSCs and sIPSCs), at least 2 min of activity (typically 100-300 events) was examined to determine hypocretin effects on amplitude and frequency distributions. The criteria for detecting synaptic currents were fast rise times $(<1 \mathrm{msec})$, exponential decays, and amplitude of at least twice the peak-to-peak baseline noise (nominally 2-4 pA). EPSCs were examined at holding potentials between rest and the calculated $\mathrm{Cl}^{-}$equilibrium potential (i.e., between approximately -50 and $-83 \mathrm{mV}$ ). IPSCs were examined at rest and at less negative holding potentials $(-30-0$ $\mathrm{mV}$ ). When present, spontaneous unclamped sodium currents were inactivated shortly after depolarizing the neurons to study IPSCs. In most experiments that examined IPSCs, cesium was present in the recording pipette, preventing repolarizing potassium currents and facilitating spike inactivation. Hypocretin 1 or 2 (orexin A or B; Sigma) was bath applied for 2-4 min at a concentration of 0.03-1 $\mu \mathrm{M}$. The $\mathrm{GABA}_{\mathrm{A}}$ antagonist, bicuculline methiodide $(30 \mu \mathrm{M})$, the glutamate AMPA/kainate receptor antagonist, 6-cyano-7-nitroquinoxaline-2,3-dione (CNQX; $10 \mu \mathrm{M})$, the NMDA receptor antagonist, 5-aminophosphonovaseric acid (APV; 50 $\mu \mathrm{M}$; receptor antagonists all from Sigma), and tetrodotoxin (TTX; $2 \mu \mathrm{M}$ ) (Sigma or Alomone Labs, Jerusalem, Israel) were added to the ACSF for some experiments. 
Glutamate photostimulation. Photoactivation of caged glutamate (i.e., glutamate photostimulation) was performed similar to previous descriptions (Callaway and Katz, 1993; Wuarin and Dudek, 2001). L-glutamic acid, $\gamma$ - $(\alpha$-carboxy-2-nitrobenzyl) ester, trifluoroacetic acid salt (i.e., CNB-caged glutamate, $250 \mu \mathrm{m}$; Molecular Probes, Eugene, OR), which does not bind to glutamate receptors, was added to recirculating, oxygenated ACSF. A xenon flash lamp ( T.I.L.L. Photonics, Eugene, OR) was used to uncage glutamate (Callaway and Katz, 1993), which allowed the molecule to activate glutamate receptors. The flash of UV light (2-3 $\mathrm{msec}$ ) was directed through the epifluorescence port of an inverted microscope (Nikon TE200, Nikon) and focused through the slice by positioning a high numerical aperture $40 \times$ oil immersion objective (Nikon) beneath the cover glass forming the floor of the recording chamber. A diode laser $(\lambda=670 \mathrm{~nm})$, which does not uncage the glutamate, was directed through the objective to aim the UV flash using the camera port on the microscope and viewed using a CCD camera attached to a dissecting microscope above the slice. The effective diameter of glutamate photolysis $(\sim 100 \mu \mathrm{m})$ was determined empirically by detecting direct inward current caused by uncaging glutamate directly under the tip of the recording pipette and then moving the flash area progressively farther away from the recording. In control experiments, there was no degradation of the direct response (i.e., the inward current) after $>100$ stimuli. The flash was directed into discrete areas to evoke glutamate-induced action potentials in NTS neurons. Once a synaptic response was detected in the DMV, a comparison of responses with 20-30 flashes was made before and after addition of hypocretin (300 nM). Because glutamate uncaging activated local circuits and usually resulted in a barrage of evoked PSCs, glutamate-evoked responses were analyzed by subtracting the baseline frequency of spontaneous PSCs before uncaging from the PSC frequency after uncaging. Therefore the frequency of glutamateevoked PSCs is defined as frequency of PSCs after uncaging minus frequency of spontaneous PSCs in the 10-30 sec before uncaging.

Statistical analysis. Effects of hypocretin on spontaneous PSC frequency and amplitude were analyzed within a recording using the Kolmogorov-Smirnov test; effects on evoked PSC amplitude and glutamateevoked EPSC frequency were analyzed using a paired two-tailed Student's $t$ test. Grouped results were compared using an unpaired twotailed Student's $t$ test or one-way ANOVA. Results are reported as the mean \pm SEM unless indicated otherwise; significance was set at $p<0.05$ for all statistical measures.

Histology and immunohistochemistry. Recording pipettes contained $0.2 \%$ biocytin, which diffused into the neuron during recording to label recorded neurons to verify their location and EGFP content post hoc. After each recording, slices were fixed in $4 \%$ paraformaldehyde (Fisher Scientific, Houston, TX) in $0.15 \mathrm{M} \mathrm{NaPO}_{4}$ buffer, $\mathrm{pH} 7.3$, overnight at $4^{\circ} \mathrm{C}$. After fixation, slices were rinsed $(3 \times 5 \mathrm{~min})$ in $0.01 \mathrm{~m} \mathrm{PBS}, \mathrm{pH} 7.4$. Reactions were performed on whole-mount specimens. To compare the recorded neuron location with that of EGFP-labeled neurons, biocytinfilled neurons were visualized by reacting the tissue with avidin-rhodamine (Vector Labs) in PBS (1:400, pH 7.3) containing $0.1-1 \%$ Triton $\mathrm{X}-100(4-12 \mathrm{hr})$. In most cases, the neurons were subsequently reacted using the $\mathrm{ABC}$ method (ABC Elite, 1:100, $2 \mathrm{hr}$ to overnight; Vector Labs). After rinsing again in PBS $(3 \times 5 \mathrm{~min})$, the labeled neurons were visualized with diaminobenzidine (DAB) at a concentration of $0.06 \%$ with $0.003 \% \mathrm{H}_{2} \mathrm{O}_{2}$ in $0.01 \mathrm{M}$ PBS. The slices were then mounted on slides (Superfrost/Plus, Fisher Scientific), air dried overnight, and then dehydrated in alcohols and covered in Permount. For purposes of assessing basic morphological characteristics, a subset of neurons was reconstructed digitally using Neurolucida v4.05c software (MicroBrightField, Williston, VT). Video images were obtained from a CCD camera (Cohu, San Diego, CA) mounted on an upright microscope with a $63 \times$ oilimmersion objective (Axioskop; Zeiss, Thornwood, NY) and motorized stage. Cell analysis was performed using Neuroexplorer 3.23b software (MicroBrightField) and was limited in this study to information on soma area, soma form factor, and number of dendrites. Hypocretin-containing elements in the brainstem were identified using a polyclonal antibody to hypocretin 2 (a gift from A. N. van den Pol, Yale University, New Haven, CT; 1:5000) or hypocretin 1 (Orexin A, 1:4000; Alpha Diagnostic International, San Antonio, TX) in PBS containing 1\% Triton X-100 over- night. Hypocretin immunoreactive fibers were visualized in conjunction with the biocytin-filled DMV neurons using a fluorescein-conjugated secondary antibody (1:200; IgG). No fiber staining was observed when the primary antibody was omitted.

\section{Results}

\section{Prelabeling of stomach-projecting neurons}

Stomach-projecting neurons in the DMV were identified after infection of the gastric musculature with a transsynaptic retrograde viral label isogenic with PRV-152 Bartha constructed to report EGFP from the human cytomegalovirus immediate early promoter (a gift from L. W. Enquist). Inoculation of the stomach wall resulted in a temporal progression of retrograde EGFP labeling of stomach-projecting autonomic circuits that was similar to that reported for PRV Bartha (Card et al., 1993; Rinaman et al., 1993). EGFP-labeled neurons of the DMV first appeared approximately $40-50 \mathrm{hr}$ after infection. Neurons in the NTS became infected approximately 12-20 hr later. Recordings included in this study were limited to infection times $<75 \mathrm{hr}$, when no apparent degradation of membrane properties was detected (Smith et al., 2000; Irnaten et al., 2001). Control injections of the virus into the lumen of the stomach $(n=3)$ or onto the surface of the stomach or peritoneum $(n=5)$ were made to determine whether axons of passage were labeled by the virus. No specific labeling was observed in the DMV after these injections, supporting previous data indicating that PRV-152 invaded the DMV after being taken up by gastric vagal terminals (Card et al., 1990).

A total of 115 neurons in the DMV (16 EGFP-labeled and 99 unlabeled) were recorded from uninfected and PRV-152infected rats. All neurons were from rostrocaudal levels of the DMV corresponding to areas with high numbers of EGFPlabeled neurons. Neurons were examined primarily in voltageclamp to determine the nature of their synaptic inputs. However, action potentials and resting membrane potential were briefly assessed in most cells by transiently removing the voltage-clamp (i.e., by switching to $I=0$ ) and monitoring voltage. All neurons examined were capable of firing action potentials with $\geq 20 \mathrm{mV}$ overshoot. Mean input resistance was $328 \pm 32 \mathrm{M} \Omega$ and resting membrane potential was $-50 \pm 3 \mathrm{mV}(n=28)$.

Gastric-related neurons were identified either by the presence of EGFP in the cell during the recording or post hoc using biocytin to double-label filled neurons that also contained EGFP (Fig. 1). There was no difference between the average input resistance, resting membrane potential, or frequency of postsynaptic currents recorded from EGFP-labeled versus unlabeled neurons (Table 1). General morphological properties of DMV neurons were also similar between labeled and unlabeled neurons and similar to those observed previously after retrograde labeling of vagal motor neurons from the stomach (Fig. 1) (Browning et al., 1999). Neuron morphology confirmed that the recordings used in this study were made from motor neurons of the DMV (Fig. 1).

\section{Hypocretin immunoreactivity and recording location}

Hypocretin-immunoreactive fibers have been observed throughout the caudal vagal complex (Peyron et al., 1998; Date et al., 1999; Nambu et al., 1999; Smith et al., 2002). In all animals examined immunohistochemically $(n=12)$, hypocretin 1 and hypocretin 2 immunoreactive fibers were observed within and near the DMV at rostrocaudal levels corresponding to those at which neurons used in this study were recorded. In seven of seven cases in which hypocretin immunohistochemistry was performed on whole-mount slices from which a whole-cell recording was made, hypocretin fibers were observed in apposition to 


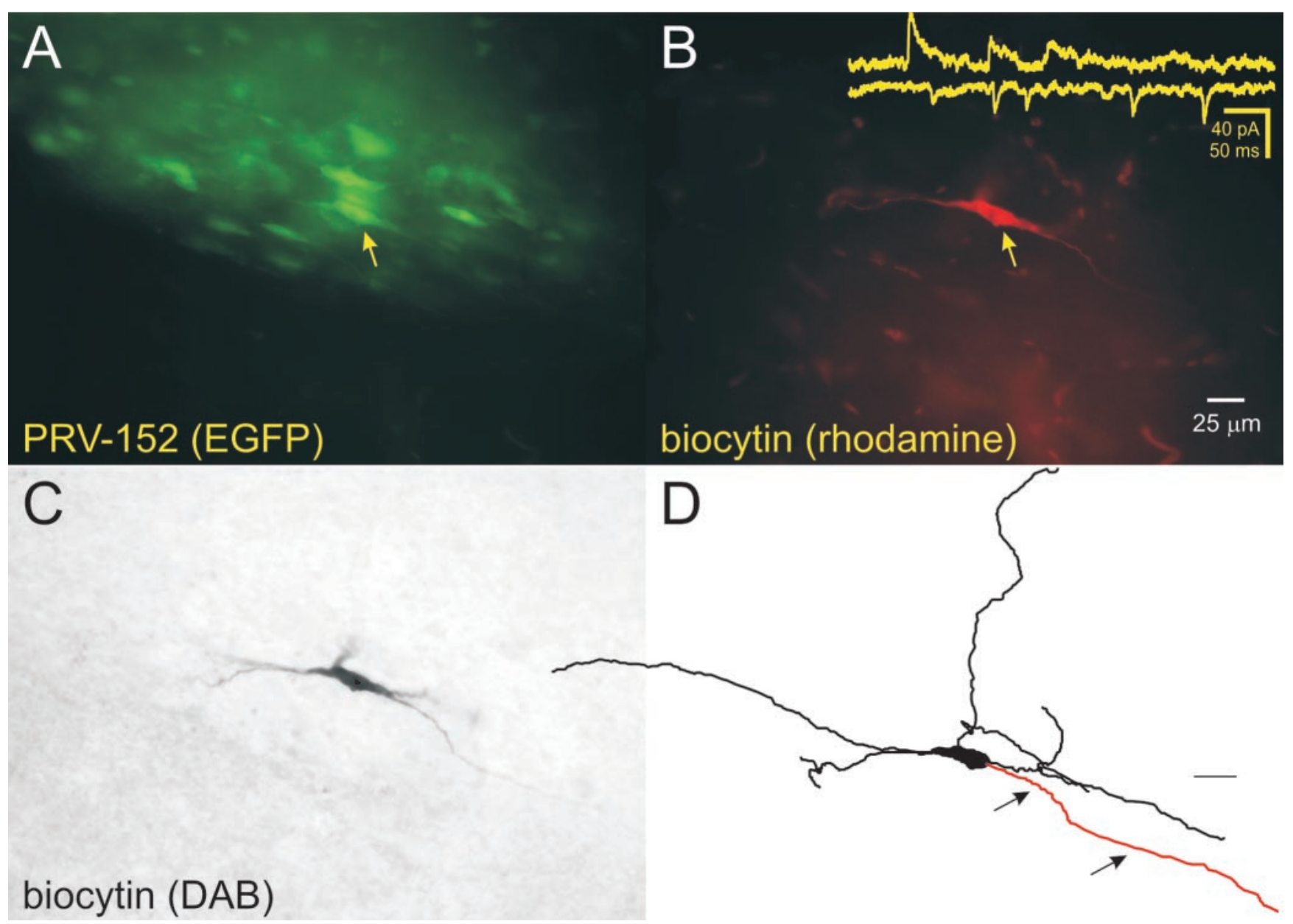

Figure 1. Patch-clamp recording from gastric-related rat DMV neurons prelabeled with PRV-152. A, Whole-mount view of a brainstem slice ( $400 \mu \mathrm{m})$ after fixation reveals EGFP-labeled DMV neurons $70 \mathrm{hr}$ after inoculation of the stomach wall. The neuron indicated (arrow) was targeted for recording and filled with biocytin. $B$, The same slice and plane of section viewed with optics demonstrating the biocytin label (i.e., avidin-rhodamine fluorescence). The filled neuron is indicated by the arrow. Inset, Examples of spontaneous EPSCs from this neuron and IPSCS from another PRV152-labeled DMV neuron. C, The same neuron in whole mount after ABC-DAB reaction. D, The same neuron was reconstructed digitally. Arrows point to the axon.

Table 1. Membrane properties and morphology of EGFP-labeled and unlabeled DMV neurons

\begin{tabular}{lcc}
\hline & Unidentified $(n)$ & EGFP labeled $(n)$ \\
\hline $\operatorname{Rin}(\mathrm{M} \Omega)$ & $336 \pm 36(16)$ & $298 \pm 39(12)$ \\
$\operatorname{RMP}(\mathrm{mV})$ & $-48 \pm 2(16)$ & $-50 \pm 2(12)$ \\
IPSC frequency $(\mathrm{Hz})$ & $1.7 \pm 0.2(29)$ & $1.4 \pm 0.3(8)$ \\
EPSC frequency $(\mathrm{Hz})$ & $2.3 \pm 0.7(9)$ & $3.2 \pm 1.0(8)$ \\
Soma area $\mu^{2}$ & $299.5 \pm 21.8(24)$ & $355.0 \pm 45.3(10)$ \\
Number of dendrites & $3.74 \pm 0.27(24)$ & $3.70 \pm 0.34(10)$ \\
\hline
\end{tabular}

the soma and dendrites of recorded neurons (Fig. $2 A$ ). In addition, dendrites of DMV cells often extended into the NTS, where hypocretin fibers are abundant (Smith et al., 2002).

\section{Hypocretin-induced changes in whole-cell current}

DMV neurons were voltage-clamped at membrane potentials between -60 and $-80 \mathrm{mV}$, and changes in whole-cell current after hypocretin application at concentrations of 100-1000 nM were observed. Hypocretin 1 or hypocretin 2 was applied at a concentration of $300 \mathrm{nM}$ to eight voltage-clamped neurons under normal recording conditions. All of the neurons examined displayed a small whole-cell current change. Application of hypocretin 1 resulted in an inward current in three of four neurons (13.3 \pm 2.2 pA). The remaining cell showed a 13 pA outward current. Simi- larly, three of four neurons showed an inward current in response to hypocretin $2(30.7 \pm 7.3 \mathrm{pA})$ (Fig. $2 B)$. The remaining neuron also exhibited a $13 \mathrm{pA}$ outward current. A hypocretin-induced small membrane potential depolarization $(3-6 \mathrm{mV})$ was also observed in 9 of 11 neurons, including three EGFP-labeled neurons, by temporarily removing the voltage clamp during hypocretin application. When $\mathrm{Cs}^{+}$was used as the dominant intracellular cation, hypocretin application failed to cause a measurable membrane current or depolarization in 17 of 18 neurons. These data indicated that gastric-projecting neurons infected with PRV-152 could generate inward currents in response to the hypocretins and were consistent with previous reports indicating that the hypocretins tend to depolarize most DMV neurons in a $\mathrm{K}^{+}$dependent manner (Hwang et al., 2001).

\section{Synaptic inputs}

Synaptic input to most DMV neurons was recorded at holding potentials that allowed separation of outward and inward currents by their polarity (Smith et al., 1998, 2002). In some neurons $(n=16)$, both sIPSCs and sEPSCs were analyzed in the same cell by first examining responses at a depolarized holding potential $(-30-0 \mathrm{mV})$ for $2-5 \mathrm{~min}$ and then reexamining the responses at a more negative potential (i.e., -80 to $-60 \mathrm{mV}$ ). In most experiments that examined IPSCs, cesium was present in the recording pipette, blocking postsynaptic leak conductance changes induced 

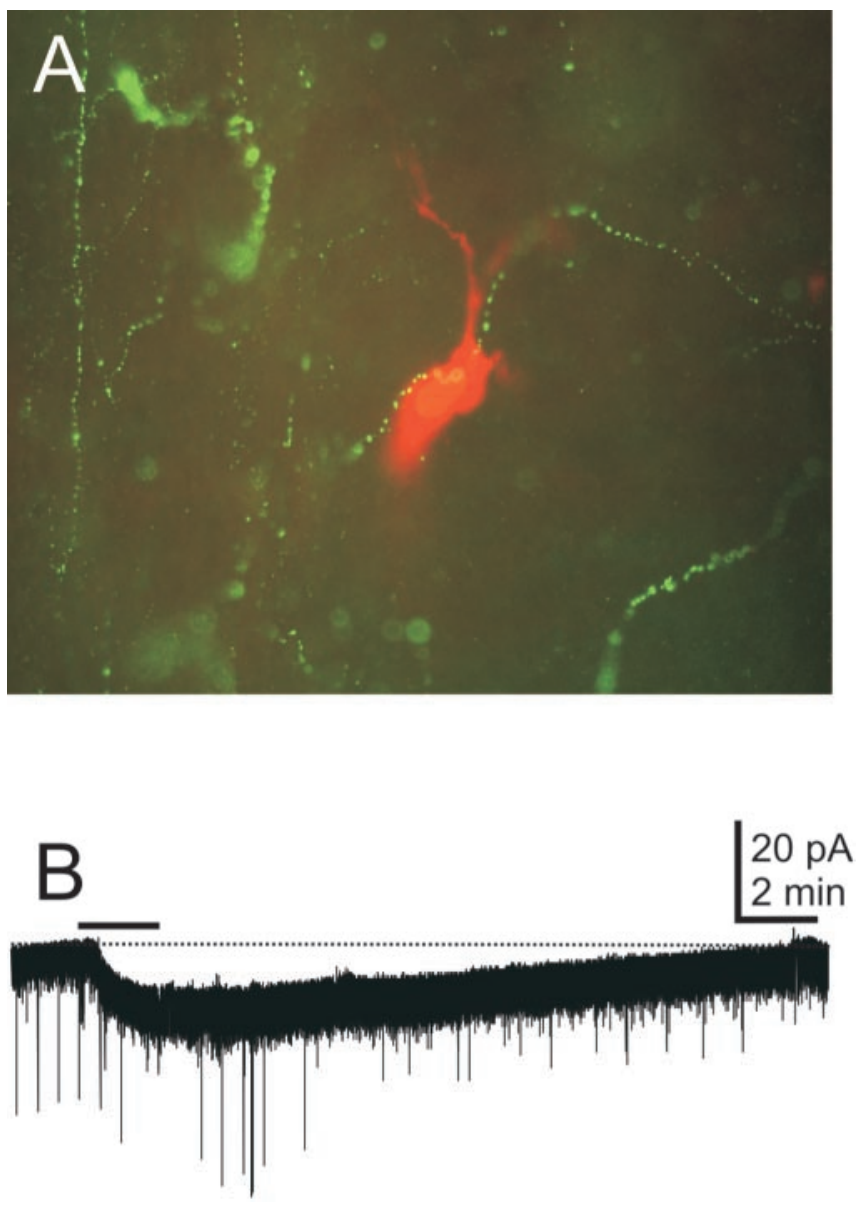

Figure 2. Hypocretin-containing fibers are present in the DMV, and the peptides have postsynaptic effects on DMV neurons. $A$, This neuron was filled with biocytin $(0.2 \%)$ during a recording and was reacted with avidin-rhodamine conjugate (red fluorescence). Hypocretin 2-immunoreactive axons were visualized with a fluorescein-conjugated secondary antibody (green fluorescence) near the recorded neuron. $B$, Hypocretin 2 application to another DMV neuron (bar) resulted in an inward current. Holding potential was $-70 \mathrm{mV}$.

by hypocretin and effectively isolating effects of the peptide to that occurring on afferent inputs. In some experiments, the AMPA receptor antagonist CNQX and the $\mathrm{GABA}_{\mathrm{A}}$ receptor antagonist bicuculline were added to the ACSF. Inward synaptic currents were blocked by CNQX (10 $\mu \mathrm{M} ; n=10)$, and outward synaptic currents were blocked by bicuculline (30 $\mu \mathrm{M} ; n=5)$. They were therefore considered to be EPSCs and IPSCs mediated by glutamatergic AMPA/kainate and $\mathrm{GABA}_{\mathrm{A}}$ receptors, respectively. The mean sEPSC frequency for all neurons was $2.8 \pm 0.6$ $\mathrm{Hz}$, and the mean amplitude, measured near resting membrane potential (approximately $-50 \mathrm{mV}$ ) was $19 \pm 1 \mathrm{pA}$. Neither the amplitude nor frequency of sEPSCs was different $(p>0.05)$ between EGFP-labeled $(n=8)$ and unlabeled $(n=9)$ neurons (Table 1). The mean sIPSC frequency for all neurons was $1.6 \pm$ $0.2 \mathrm{~Hz}$, and the mean amplitude at holding potentials near rest was $26 \pm 2 \mathrm{pA}$. Neither the amplitude nor frequency of sIPSCs was different $(p>0.05)$ between EGFP-labeled $(n=8)$ and unlabeled $(n=29)$ neurons (Table 1$)$. These findings were consistent with previous reports, which indicated minimal morphological or physiological effects of PRV-152 in early stage infections (Rinaman et al., 1993). These data also indicated that membrane properties and synaptic input of EGFP-labeled DMV neurons remained quantitatively similar to unlabeled neurons 75 $\mathrm{hr}$ after stomach inoculation.

\section{Hypocretin effects on spontaneous IPSCs}

The effect of the hyopcretins on sIPSCs was studied on 25 neurons of the DMV, 8 of which were EGFP-labeled, 60-72 hr after inoculation of the stomach wall with PRV-152. The frequency and amplitude of sIPSCs was examined at holding potentials of $-30-0 \mathrm{mV}$, usually using $\mathrm{Cs}^{+}$as the primary cation carrier in the pipette to isolate peptide effects on afferent neurons and terminals from possible effects at soma-dendritic receptors on the recorded neuron. The frequency of sIPSCs was significantly and reversibly increased by both hypocretins in a concentrationrelated manner $(0.3-1 \mu \mathrm{M})$ in each of the 25 neurons (Fig. 3), including 8 cells recorded with $\mathrm{K}^{+}$in the pipette that were also depolarized by the same application of the peptide. At a concentration of $1 \mu \mathrm{M}$, hypocretin $2(n=10)$ increased the frequency of sIPSCs $13-477 \%(184 \pm 18 \% ; p<0.05)$, and hypocretin $1(n=$ 11 ) increased the frequency of sIPSCs $42-351 \%$ (155 $\pm 14 \% ; p<$ $0.05)$. Additional experiments were performed in the presence of $10 \mu \mathrm{M}$ CNQX, producing similar results (178 $\pm 53 \%$ increase; $n=6)$. The amplitude of sIPSCs was not significantly altered by either peptide at this concentration $(5 \pm 5 \%$ for hypocretin 1 ; $-6 \pm 6 \%$ for hypocretin $2 ; p>0.05)$.

\section{Effects on miniature IPSCs}

To determine whether the enhanced IPSC activity was caused by $\mathrm{Na}^{+}$-independent release from synaptic terminals, slices were bathed in TTX $(2 \mu \mathrm{M})$ to block action potential-dependent release of neurotransmitter. The effect of hypocretin on resulting miniature IPSCs (mIPSCs) was studied in 20 neurons, including 6 EGFP-labeled neurons in the presence of TTX. At a concentration of $1 \mu \mathrm{M}$, hypocretin 1 significantly increased the frequency of mIPSCs in 9 of 13 neurons in the presence of TTX, including 2 of 3 EGFP-labeled cells. The mean increase for these nine cells was $29 \pm 4 \%(p<0.05)$ and was unchanged in the remaining four neurons. Hypocretin 2 significantly and reversibly increased the frequency of mIPSCs in each of seven neurons by an average of $182 \pm 31 \%$ (Fig. 4). The amplitude of mIPSCs was unchanged by either peptide $(0 \pm 2 \%$ for hypocretin $1 ;-4 \pm 4.5 \%$ for hypocretin $2 ; p>0.05)$. The mean change in mIPSC frequency was significant for both peptides, suggesting the possibility that hypocretin enhanced IPSCs because of a presynaptic mechanism. The enhancement of mIPSC frequency by hypocretin 1 was significantly less than for sIPSCs in the absence of TTX $(p<0.05)$, suggesting the possibility that the peptide also increased action potential activity in some afferent neurons.

\section{Effects on spontaneous EPSCs}

The effect of hypocretin on sEPSCs was examined in 10 neurons, 3 of which were EGFP-labeled (Fig. 5). Hypocretin 1 or $2(1 \mu \mathrm{M})$ had no effect on sEPSC frequency in 8 of 10 neurons, including 4 neurons in which an increase in sIPSC frequency was also observed during the same application. Each peptide increased slightly the frequency of sEPSCs in one cell (67 and 55\%); none of the EGFP-labeled neurons were affected. The amplitude of sEPSCs was also unchanged by the hypocretins $(1 \pm 6 \%$ overall increase; $p>0.05$ ).

\section{Electrical stimulation of the NTS}

Electrical stimulation was used to examine the effect of the hypocretins on NTS-evoked IPSCs and EPSCs (eIPSCs and eEPSCs). Hypocretin 2 (300 nM) caused an increase in eIPSC amplitude in three of six neurons tested $(21.4 \pm 3.7 \%$ increase; $p<0.05)$ (Fig. $6)$. The eIPSC amplitudes in the remaining neurons were unchanged. The effect of hypocretin 1 was more variable. Hypocre- 


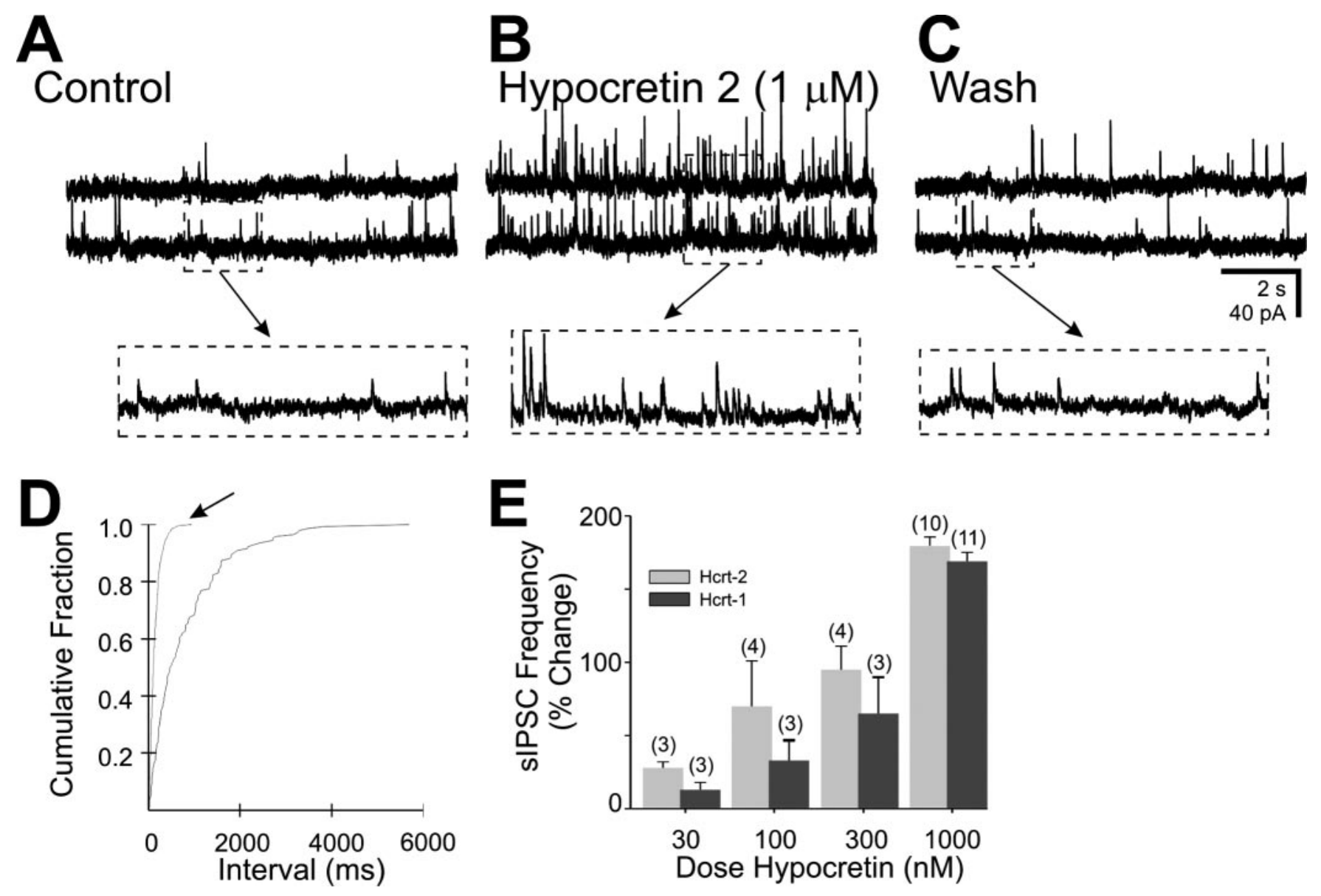

Figure 3. The effect of hypocretin on spontaneous IPSCs in the DMV. A, Spontaneous IPSCS were observed in this neuron at a holding potential of $-10 \mathrm{mV}$. $B$, The same neuron in the presence of hypocretin $2(1 \mu \mathrm{M})$. C, Twenty minute wash to normal ACSF. Arrows point to temporally expanded regions of the traces in $A-C$, as indicated. This cell was prelabeled by inoculation of the stomach wall with PRV-152. D, Cumulative fraction plot indicates a significant increase in IPSC frequency by hypocretin 2 (arrow) $(p<0.05$; Kolmogorov-Smirnov test). E, The increase in frequency was related to peptide concentration for both hypocretin 1 and 2 . The number of cells is indicated in parentheses above each set of data.

tin 1 ( $300 \mathrm{~nm}$ ) had no effect in two of four neurons examined. The remaining two cells showed an increase and decrease (19.1 and $-26.7 \%)$ in electrically evoked IPSC amplitude. In some experiments $(n=8)$, CNQX $(10 \mu \mathrm{M})$ was added to pharmacologically isolate the hypocretin effect on evoked IPSCs. The same concentration of hypocretin 2 enhanced eIPSCs to a similar but variable extent in four cells recorded in the presence of CNQX (133 \pm $37.0 \%$ increase), with eIPSC amplitudes in the remaining cells being unaltered $(n=3)$ or decreased $(17 \% ; n=1)$. The effect of the hypocretins was also examined on eEPSCs in nine neurons. Neither hypocretin $1(n=5)$ nor hypocretin $2(n=4)$ was found to have an effect on the amplitude of EPSCs evoked by electrical stimulation of the NTS (Fig. 6). These data suggest that at least a portion of the inhibitory input to the DMV that was enhanced by the hypocretins could be activated by electrically stimulating the NTS.

\section{Chemical microstimulation in the NTS}

Electrical stimulation of the NTS should depolarize the soma and dendrites of intact neurons, but it also activates fibers of passage traversing the NTS, which may arise from many CNS regions. To identify effects of hypocretin 2 specifically on projections to the DMV that arise from inhibitory neurons in the NTS, we used glutamate photostimulation to microapply glutamate at discrete sites in the NTS. Focal uncaging of glutamate in the NTS increased IPSC frequency above baseline for between 200 and 800 msec after uncaging. The increased IPSC frequency likely represents the activation of local inhibitory circuits originating in the region of glutamate uncaging. Inhibitory synaptic responses to glutamate photostimulation of medial or dorsal NTS areas were examined in seven DMV neurons. Application of hypocretin 2 (300 nM) significantly increased the frequency of glutamate photolysis-evoked IPSCs in each of the seven neurons (360 \pm $114 \%$ over control; $p<0.05$ ) (Fig. 7). The glutamate photostimulation-evoked increase in IPSC frequency was abolished when the slice was bathed in $2 \mu \mathrm{M}$ TTX $(n=4)$ (Fig. 7), confirming that the increased IPSC frequency resulted from action potential generation in NTS neurons and not simply increased transmitter release caused by activation of receptors on terminals. A TTX-resistant inward current was sometimes associated with the glutamate uncaging and probably represented activation of receptors on the DMV neuron dendrites, which often extend into the NTS. These data indicated that hypocretin 2 enhanced inhibitory input to the DMV arising specifically from activity in NTS neurons.

\section{Discussion}

The hypocretins exert primarily excitatory actions on neurons in multiple brain areas. In agreement with a previous finding that hypocretin depolarized DMV neurons (Hwang et al., 2001), we report a hypocretin-induced inward current, including in neurons that control the stomach. In contrast, hypocretin also con- 
A

\section{Control}

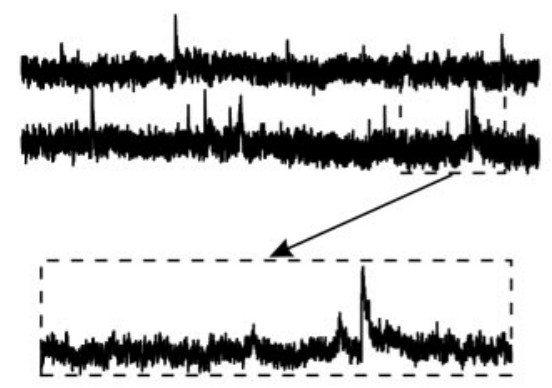

D

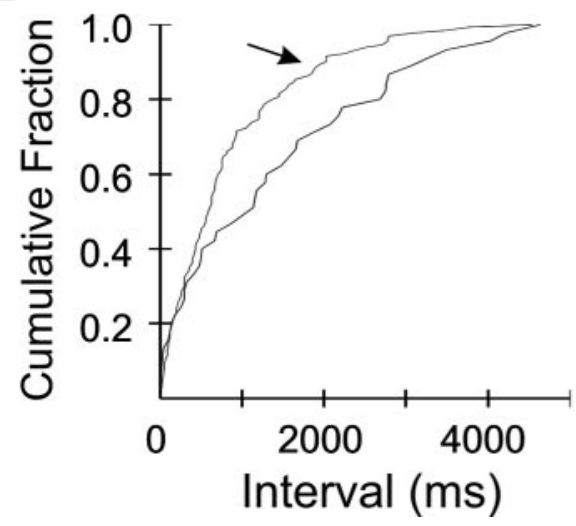

B

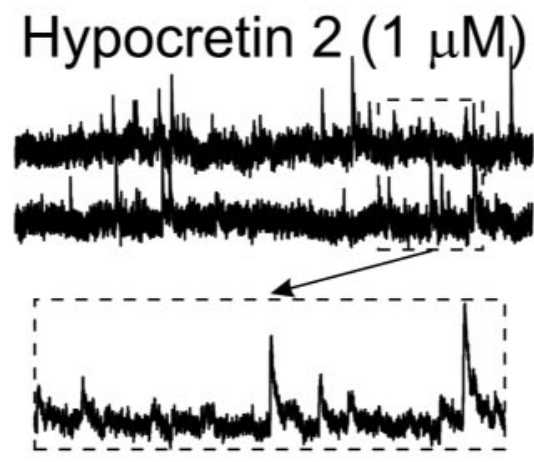

C

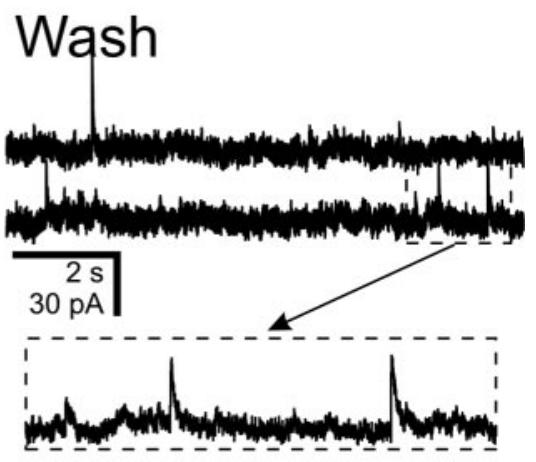

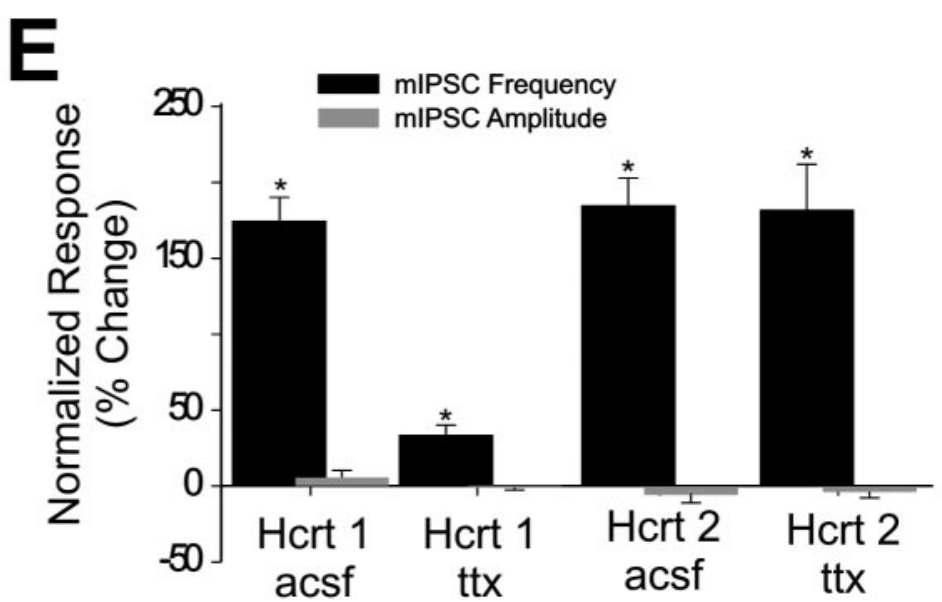

Figure 4. The effect of hypocretin on mIPSCs in the DMV in the presence of $2 \mu \mathrm{M}$ TTX. A, Spontaneous mIPSCs were observed in this neuron at a holding potential of $-5 \mathrm{mV} . B$, The same neuron in the presence of hypocretin $2(1 \mu \mathrm{M})$. C, Twenty-five minute wash to ACSF with TTX. Arrows point to temporally expanded regions of the traces in $A-C$, as indicated. This cell was prelabeled by inoculation of the stomach wall with PRV-152. D, Cumulative fraction plot indicates a significant increase in mIPSC frequency by hypocretin 2 (arrow) $(p<0.05)$. E, Plots indicating frequency and amplitude changes observed after $1 \mu \mathrm{m}$ hypocretin 1 and 2 application for several neurons. Asterisks indicate significant changes $(p<0.05)$ for frequency but not amplitude.

sistently enhanced inhibitory, but not excitatory, fast synaptic inputs to these neurons, including those that were depolarized by the peptide. At least a portion of this modulation appeared to involve activation of receptors on presynaptic terminals. In addition, we demonstrated that inhibitory inputs arising specifically from neurons in the NTS are enhanced by the peptides. Axons containing hypocretin, and message for both types of hypocretin receptor, have recently been identified in the DVC (Peyron et al., 1998; Date et al., 1999; Marcus et al., 2001), and our immunohistochemical analyses confirmed the presence of hypocretin peptides in axons within the DMV. The specific effects on gastricrelated and unidentified neurons in the DMV are consistent with the hypothesis that there is a functional pairing of the hypocretin system with visceral motor control, including control of the gastric musculature.

Because of the reported effects of hypocretin on feeding and gastric function (Sakurai et al., 1998; Rodgers et al., 2000; Krowicki et al., 2002), neurons specifically involved in motor control of the stomach were targeted for recording using the EGFP-reporting retrograde tracer, PRV-152. As in previous analyses (Smith et al., 2000; Irnaten et al., 2001), the use of PRV-152 allowed identification of a relevant subset of neurons within a functionally heterogeneous group of neurons in the slice. Basic membrane properties and morphology, synaptic input patterns, and feeding behavior were not adversely affected by the label at the time periods used (i.e., $<75 \mathrm{hr}$ after inoculation). The effects of hypocretin on EGFP-labeled cells were identical to those in cells from uninfected animals, indicating that cellular responses to hypocretin, which involve G-protein-mediated intracellularsignaling mechanisms (de Lecea et al., 1998; Sakurai et al., 1998; Hwang et al., 2001) were intact.

\section{Membrane effects}

A previous study showed that the hypocretins tended to depolarize most DMV neurons projecting to the abdominal viscera via a $\mathrm{K}^{+}$- and $\mathrm{Na}^{+}$-dependent postsynaptic mechanism (Hwang et al., 2001). The TTX-resistant inward current that we observed was likely analogous to this direct depolarization. The high proportion of neurons responding here may be a reflection of our use of voltage clamp to uncover small inward currents. Depolarization or inward current induction by hypocretin has also been demonstrated in several other CNS regions (Horvath et al., 1999; Shirasaka et al., 1999; Brown et al., 2001; Eggermann et al., 2001; Eriksson et al., 2001; Burlet et al., 2002; Samson et al., 2002; Smith et al., 2002; van den Pol et al., 2002; Yang and Ferguson, 2002). The depolarization involves reduction of a $\mathrm{K}^{+}$conductance in some cells but may also activate a nonspecific cation current or electrogenic $\mathrm{Na}^{+} / \mathrm{Ca}^{2+}$ pump (Eriksson et al., 2001; Hwang et al., 2001; Yang and Ferguson, 2002). In this study, the peptideinduced inward current was not observed when $\mathrm{Cs}^{+}$was used intracellularly, consistent with the hypothesis that the direct 

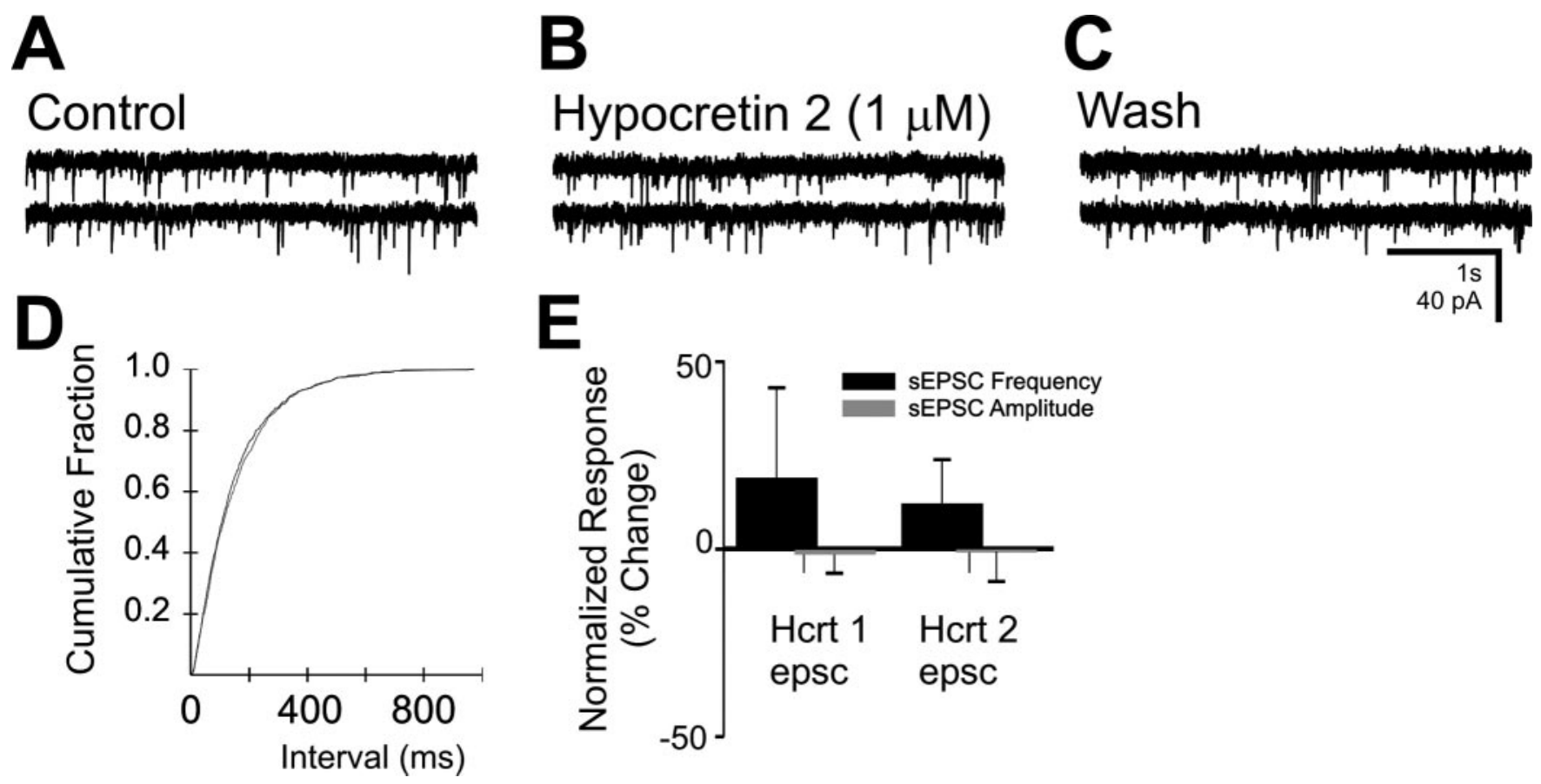

Figure 5. The effect of hypocretin on spontaneous EPSCS in the DMV. A, Spontaneous EPSCs were observed in this neuron at a holding potential of $-75 \mathrm{mV}$. $B$, The same neuron in the presence of hypocretin $2(1 \mu \mathrm{M})$. C, Twenty minute wash to normal ACSF. This cell was prelabeled by inoculation of the stomach wall with PRV-152.D, Cumulative fraction plot indicates no significant change in sIPSC frequency by hypocretin 2. E, Plots for frequency and amplitude changes after hypocretin 1 and 2 application $(1 \mu \mathrm{m})$ for several neurons. No significant changes in EPSC amplitude or frequency were observed for either peptide.

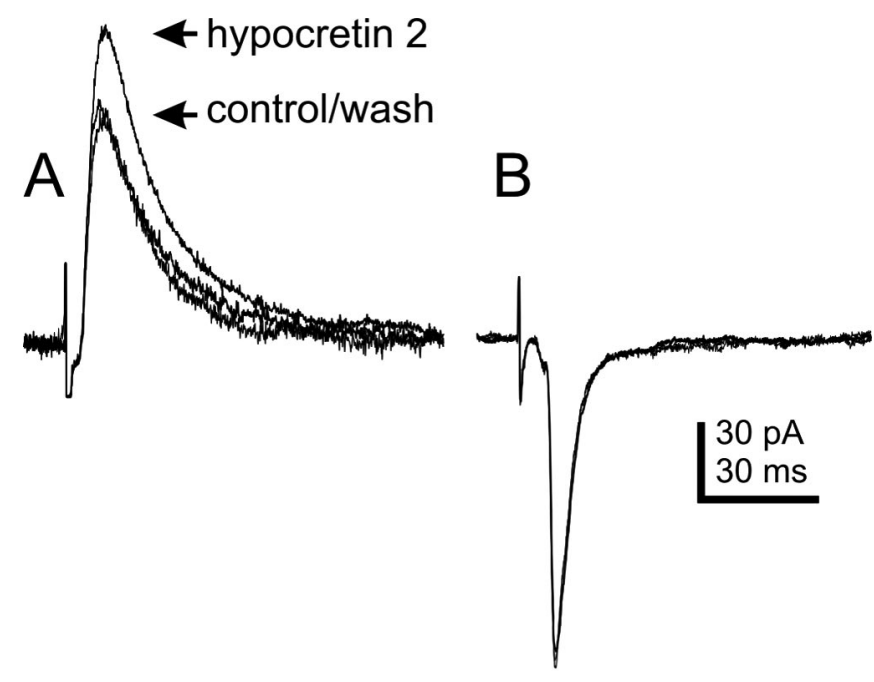

Figure 6. Effect of hypocretin on isolated IPSCS and EPSCs electrically evoked from the NTS. A, Three overlapping averaged traces showing NTS-evoked IPSCS recorded at a holding potential of $-30 \mathrm{mV}$. Arrows indicate the peaks of averaged IPSCs for control ACSF, 300 nm hypocretin 2, and 20 min after wash to control ACSF. Control ACSF contained $10 \mu \mathrm{m} \mathrm{CNQX} \mathrm{and} 50 \mu \mathrm{M} \mathrm{APV;}$ recording pipette contained $\mathrm{Cs}^{+}$. Averages of $10-12$ traces are shown for each condition. $B_{\text {, }}$ Three overlapping averaged traces showing NTS-evoked EPSCs in the DMV. Responses obtained in control ACSF, hypocretin 2 ( $300 \mathrm{~nm}$ ), and after 20 min wash to control ACSF are overlapped. The neuron was voltage-clamped at $-60 \mathrm{mV}$. Control ACSF contained $30 \mu \mathrm{m}$ bicuculline; averages of $20-25$ individual responses are shown.

membrane effects of hypocretins near resting membrane potential were $\mathrm{K}^{+}$dependent.

\section{Synaptic effects}

The other principal effect of hypocretin was an enhancement of sIPSC frequency in the absence of a significant effect on sEPSCs.
In several brain areas, the hypocretins increase excitatory or inhibitory amino acid-mediated synaptic transmission by postsynaptic actions on local circuit neurons (van den Pol et al., 1998; Burlet et al., 2002; Grudt et al., 2002; Liu et al., 2002) or by enhancing release at synaptic terminals (van den Pol et al., 1998; Smith et al., 2002). The enhanced IPSC frequency in the DMV appeared to involve peptide binding at presynaptic terminals because it was maintained after blocking action potentialdependent neurotransmitter release with TTX. Hypocretin 1 activates both hypocretin receptors (HcrtR1 and HcrtR2) with near equal affinity, whereas hypocretin 2 preferentially binds to HcrtR2 (Sakurai et al., 1998). Both peptides were effective in enhancing IPSCs, but a larger proportion of the hypocretin 2 effect was TTX resistant. Separating effects on individual receptors will be facilitated by specific antagonists for each receptor, which are not readily available. Combined with the depolarization, the finding that inhibitory input to most DMV neurons was enhanced, whereas excitatory input was not, suggests a complex interaction between the descending hypocretin system and vagal motor output.

\section{Modulation of reflex activity}

Vagal motor neurons project to most visceral systems and subserve various functional modalities for those systems. The population of neurons projecting to the gastric corpus is responsible for integrating signals related to gastric contraction, distention, and acid secretion, which may all be regulated by hypocretins (Takahashi et al., 1999; Krowicki et al., 2002). Central infusion of hypocretin activates c-fos in a few DMV neurons (Date et al., 1999), supporting the hypothesis that the peptides can excite otherwise metabolically quiescent cells. Conversely, DMV neurons are often reflexively inhibited during gastric or esophageal distention (McCann and Rogers, 1992; Fogel et al., 1996; Rogers et al., 1999), when activation of excitatory vagal afferents releases 

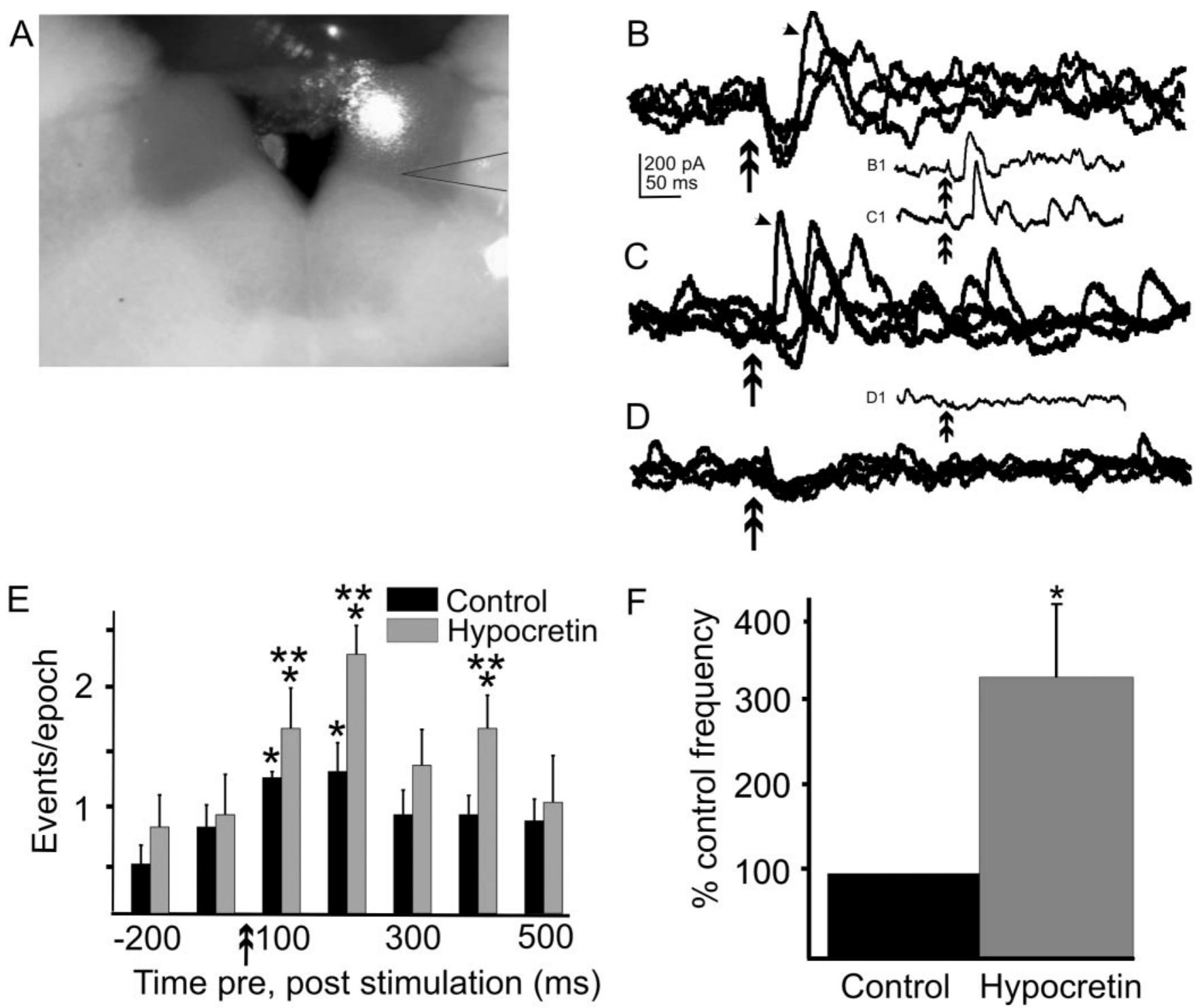

Figure 7. Effect of hypocretin on IPSCs evoked by glutamate photolysis in the NTS. A, Digital image of $400 \mu \mathrm{m}$ rat brainstem slice with a recording pipette in the DMV. A spot of visible light was used to aim the UV flash for uncaging of glutamate. The spot on the tissue was larger than the effective area of uncaging. In this case, uncaging occurred (i.e., glutamate was released) in the dorsomedial NTS. The recording pipette has been outlined to clarify its position. B, Overlapping traces $(n=4)$ illustrating IPSCs evoked in the DMV after glutamate photolysis at the position illustrated in $A$. The downward deflections represent either a direct effect of the glutamate on dendrites of the recorded neuron or an EPSC. B1, The single trace indicated by an arrow in $B$, separated to show an individual response. C, Overlapping traces in the same neuron $3 \mathrm{~min}$ after the addition of $300 \mathrm{~nm}$ hypocretin 2 to the ACSF. Glutamate was uncaged in exactly the same position within the NTS as in $B$. C1, The single trace indicated by an arrow in C. D, Four overlapping traces from the same neuron after addition of $2 \mu \mathrm{m} \mathrm{TTX}$ and photostimulation at the same position as $B$ and $C$. The remaining inward current is likely attributable to a direct effect of glutamate on dendrites of the recorded neuron. D1, Example of an individual response to photostimulation in the presence of TTX. Double arrow in all records indicates glutamate stimulus ( $2 \mathrm{msec}$ flash); holding potential was $-25 \mathrm{mV}$. E, Peristimulus histogram showing the average number of IPSCs over $10-20$ traces for the same neuron shown in $B-D$ organized into $100 \mathrm{msec}$ epochs in control and hypocretin-containing ACSF. Glutamate photostimulation time is indicated by the double arrows. Single asterisks indicate significance relative to prestimulus values; double asterisks indicate periods of significantly greater evoked responses obtained in the presence of hypocretin versus control ACSF ( $p<0.05)$. $F$, Effect of hypocretin on frequency of glutamate-evoked IPSCs across seven neurons, corrected for spontaneous PSC frequency. Values for the hypocretin effect are normalized to control responses.

glutamate onto NTS neurons (Smith et al., 1998). Electrical stimulation of the NTS can synaptically inhibit or excite DMV cells (Travagli et al., 1991). With the caveat that electrical stimulation of the NTS probably activates fibers of passage unrelated to NTS output, our finding that hypocretin increased the amplitude of IPSCs evoked by electrically stimulating the NTS, but not EPSCs, is consistent with the hypothesis that hypocretin might enhance reflexive inhibition of the DMV. This hypothesis is supported more directly by the finding that hypocretin increased the frequency of IPSCs evoked by uncaging glutamate in the NTS, most likely by enhancing the output of GABAergic NTS neurons projecting to the DMV. This could be attributable to activation of either receptors located on GABAergic terminals in the DMV or to excitation of NTS neurons (Smith et al., 2002). Mechanistically, this would be consistent with the hypothesis that hypocretin can act in the DVC to attenuate or delay gastric-initiated satiety signaling (Rodgers et al., 2000).

The effects of hypocretin in the DMV may also reflect an integrative role for the peptides in coordinating autonomic outflow. We observed effects of the peptides on identified DMV neurons projecting to the stomach, but the hypocretin effects may not be specific to gastric-projecting neurons. In addition to its effects on feeding behavior, hypocretin also modulates cardiovascular and sympathetic functions (Shirasaka et al., 1999; Chen 
et al., 2000) and has been proposed to coordinate autonomic tone with arousal (Mieda and Yanagisawa, 2002; Sutcliffe and de Lecea, 2002). Hypocretin modulation of segregated inputs to the DMV could contribute to coordination of autonomic outflow by modulating parasympathetic motor neuron activity.

\section{Excitation or inhibition?}

These data indicate that the same functional set of neurons was simultaneously excited and inhibited by hypocretin. The inward current would tend to depolarize DMV neurons, whereas the enhanced frequency of IPSCs would tend to be inhibitory. These seemingly contradictory effects may reflect the diversity of preganglionic vagal neuron function, even for neurons with a common target (i.e., the stomach). Bath-applied hypocretin in slices would bind to all receptors, but activation of specific descending inputs in the intact animal could differentially activate one type of response. Effects on DMV motor output may therefore depend on topographically specific inputs. For example, hypocretin might have postsynaptic effects on one set of neurons and presynaptic effects on another set, depending on the requirements of the system at the time. This hypothesis is consistent with findings that hypocretin can increase or decrease feeding depending on the activity state of the animal (Rodgers et al., 2000). Alternatively, the functional state of the individual DMV neuron could determine the cellular response to binding of both presynaptic and postsynaptic receptors. The inward current and depolarization may be most relevant to a neuron when it is inactive, thereby increasing the likelihood of action potential generation. Enhanced inhibitory inputs in a quiescent cell would have little overt effect on neuronal activity and thus on parasympathetic outflow. However, an increase in IPSC frequency could have significant effects on neurons that were already depolarized (and thus further from $\mathrm{Cl}^{-}$equilibrium). In this scenario, hypocretin may be considered to regulate the operational range of membrane potentials for DMV neurons. Whether both effects occur simultaneously in the same neuron or are independently regulated by specific descending inputs in vivo, the finding that both excitatory postsynaptic and inhibitory presynaptic responses can be generated implies that hypocretin modulates specific physiological functions of the DMV, even if specific modulation of one neuron type is not evident in the slice preparation.

The hypocretins have been broadly implicated in control of several neurological functions. This study indicates that hypocretins are anatomically positioned to modulate parasympathetic output. Unlike most systems, hypocretin selectively enhances inhibitory drive to gastric-related and other caudal vagal motor neurons, in addition to more typical depolarizing effects. The selective inhibition supports a specific role for the hypocretins in regulating gastric function, modulating reflexive feeding and satiety signaling, and possibly integrating autonomic functions.

\section{References}

Brown RE, Sergeeva O, Eriksson KS, Haas HL (2001) Orexin A excites serotonergic neurons in the dorsal raphe nucleus of the rat. Neuropharmacology 40:457-459.

Browning KN, Travagli RA (1999) Characterization of the in vitro effects of 5-hydroxytryptamine (5-HT) on identified neurones of the rat dorsal motor nucleus of the vagus (DMV). Br J Pharmacol 128:1307-1315.

Browning KN, Kalyuzhny AE, Travagli RA (2002) Opioid peptides inhibit excitatory but not inhibitory synaptic transmission in the rat dorsal motor nucleus of the vagus. J Neurosci 22:2998-3004.

Burlet S, Tyler CJ, Leonard CS (2002) Direct and indirect excitation of laterodorsal tegmental neurons by hypocretin/orexin peptides: implications for wakefulness and narcolepsy. J Neurosci 22:2862-2872.

Callaway EM, Katz LC (1993) Photostimulation using caged glutamate re- veals functional circuitry in living brain slices. Proc Natl Acad Sci USA 90:7661-7665.

Card JP, Rinaman L, Schwaber JS, Miselis RR, Whealy ME, Robbins AK, Enquist LW (1990) Neurotropic properties of pseudorabies virus: uptake and transneuronal passage in the rat central nervous system. J Neurosci 10:1974-1994.

Card JP, Rinaman L, Lynn RB, Lee BH, Meade RP, Miselis RR, Enquist LW (1993) Pseudorabies virus infection of the rat central nervous system: ultrastructural characterization of viral replication, transport, and pathogenesis. J Neurosci 13:2515-2539.

Chen CT, Hwang LL, Chang JK, Dun NJ (2000) Pressor effects of orexins injected intracisternally and to rostral ventrolateral medulla of anesthetized rats. Am J Physiol Regul Integr Comp Physiol 278:R692-R697.

Date Y, Ueta Y, Yamashita H, Yamaguchi H, Matsukura S, Kangawa K, Sakurai T, Yanagisawa M, Nakazato M (1999) Orexins, orexigenic hypothalamic peptides, interact with autonomic, neuroendocrine and neuroregulatory systems. Proc Natl Acad Sci USA 96:748-753.

de Lecea L, Kilduff TS, Peyron C, Gao X, Foye PE, Danielson PE, Fukuhara C, Battenberg EL, Gautvik VT, Bartlett Jr FS, Frankel WN, van den Pol AN, Bloom FE, Gautvik KM, Sutcliffe JG (1998) The hypocretins: hypothalamus-specific peptides with neuroexcitatory activity. Proc Natl Acad Sci USA 95:322-327.

Dube MG, Kalra SP, Kalra PS (1999) Food intake elicited by central administration of orexins/hypocretins: identification of hypothalamic sites of action. Brain Res 842:473-477.

Eggermann E, Serafin M, Bayer L, Machard D, Saint-Mleux B, Jones BE, Muhlethaler M (2001) Orexins/hypocretins excite basal forebrain cholinergic neurones. Neuroscience 108:177-181.

Eriksson KS, Sergeeva O, Brown RE, Haas HL (2001) Orexin/hypocretin excites the histaminergic neurons of the tuberomammillary nucleus. J Neurosci 21:9273-9279.

Fogel R, Zhang X, Renehan WE (1996) Relationships between the morphology and function of gastric and intestinal distention-sensitive neurons in the dorsal motor nucleus of the vagus. J Comp Neurol 364:78-91.

Gerashchenko D, Kohls MD, Greco M, Waleh NS, Salin-Pascual R, Kilduff TS, Lappi DA, Shiromani PJ (2001) Hypocretin-2-saporin lesions of the lateral hypothalamus produce narcoleptic-like sleep behavior in the rat. J Neurosci 21:7273-7283.

Grudt TJ, van den Pol AN, Perl ER (2002) Hypocretin-2 (orexin-B) modulation of superficial dorsal horn activity in rat. J Physiol (Lond) 538:517-525.

Hagan JJ, Leslie RA, Patel S, Evans ML, Wattam TA, Holmes S, Benham CD, Taylor SG, Routledge C, Hemmati P, Munton RP, Ashmeade TE, Shah AS, Hatcher JP, Hatcher PD, Jones DN, Smith MI, Piper DC, Hunter AJ, Porter RA, Upton N (1999) Orexin A activates locus coeruleus cell firing and increases arousal in the rat. Proc Natl Acad Sci USA 96:10911-10916.

Harrison TA, Chen CT, Dun NJ, Chang JK (1999) Hypothalamic orexin A-immunoreactive neurons project to the rat dorsal medulla. Neurosci Lett 273:17-20.

Horvath TL, Peyron C, Diano S, Ivanov A, Aston-Jones G, Kilduff TS, van den Pol AN (1999) Hypocretin (orexin) activation and synaptic innervation of the locus coeruleus noradrenergic system. J Comp Neurol 415:145-159.

Hwang LL, Chen CT, Dun NJ (2001) Mechanisms of orexin-induced depolarizations in rat dorsal motor nucleus of vagus neurones in vitro. J Physiol (Lond) 537:511-520.

Irnaten M, Neff RA, Wang J, Loewy AD, Mettenleiter TC, Mendelowitz D (2001) Activity of cardiorespiratory networks revealed by transsynaptic virus expressing GFP. J Neurophysiol 85:435-438.

Jons A, Mettenleiter TC (1997) Green fluorescent protein expressed by recombinant pseudorabies virus as an in vivo marker for viral replication. J Virol Methods 66:283-292.

Krowicki ZK, Burmeister MA, Berthoud HR, Scullion RT, Fuchs K, Hornby PJ (2002) Orexins in rat dorsal motor nucleus of the vagus potently stimulate gastric motor function. Am J Physiol Gastrointest Liver Physiol 283:G465-G472.

Lin L, Faraco J, Li R, Kadotani H, Rogers W, Lin X, Qiu X, de Jong PJ, Nishino S, Mignot E (1999) The sleep disorder canine narcolepsy is caused by a mutation in the hypocretin (orexin) receptor 2 gene. Cell 98:365-376.

Liu R, van den Pol AN, Aghajanian G (2002) Hypocretins (orexins) regulate serotonin neurons in the dorsal raphe nucleus by excitatory direct and inhibitory indirect actions. J Neurosci 22:9453-9464. 
Marcus JN, Aschkenasi CJ, Lee CE, Chemelli RM, Saper CB, Yanagisawa M, Elmquist JK (2001) Differential expression of orexin receptors 1 and 2 in the rat brain. J Comp Neurol 435:6-25.

McCann MJ, Rogers RC (1992) Impact of antral mechanoreceptor activation on the vago-vagal reflex in the rat: functional zonation of responses. J Physiol (Lond) 453:401-411.

Mieda M, Yanagisawa M (2002) Sleep, feeding, and neuropeptides: roles of orexins and orexin receptors. Curr Opin Neurobiol 12:339-345.

Nambu T, Sakurai T, Mizukami K, Hosoya Y, Yanagisawa M, Goto K (1999) Distribution of orexin neurons in the adult rat brain. Brain Res 827:243-260

Peyron C, Tighe DK, van den Pol AN, de Lecea L, Heller HC, Sutcliffe JG, Kilduff TS (1998) Neurons containing hypocretin (orexin) project to multiple neuronal systems. J Neurosci 18:9996-10015.

Pickard GE, Smeraski CA, Tomlinson CC, Banfield BW, Kaufman J, Wilcox CL, Enquist LW, Sollars PJ (2002) Intravitreal injection of the attenuated pseudorabies virus PRV Bartha results in infection of the hamster suprachiasmatic nucleus only by retrograde transsynaptic transport via autonomic circuits. J Neurosci 22:2701-2710.

Rinaman L, Card JP, Enquist LW (1993) Spatiotemporal responses of astrocytes, ramified microglia, and brain macrophages to central neuronal infection with pseudorabies virus. J Neurosci 13:685-702.

Rodgers RJ, Halford JC, Nunes de Souza RL, Canto de Souza AL, Piper DC, Arch JR, Blundell JE (2000) Dose-response effects of orexin-A on food intake and the behavioural satiety sequence in rats. Regul Pept 96:71-84.

Rogers RC, Hermann GE, Travagli RA (1999) Brainstem pathways responsible for oesophageal control of gastric motility and tone in the rat. J Physiol (Lond) 514:369-383.

Sakurai T, Amemiya A, Ishii M, Matsuzaki I, Chemelli RM, Tanaka H, Williams SC, Richarson JA, Kozlowski GP, Wilson S, Arch JR, Buckingham RE, Haynes AC, Carr SA, Annan RS, McNulty DE, Liu WS, Terrett JA, Elshourbagy NA, Bergsma DJ, Yanagisawa M (1998) Orexins and orexin receptors: a family of hypothalamic neuropeptides and G-proteincoupled receptors that regulate feeding behavior. Cell 92:573-585.

Samson WK, Taylor MM, Follwell M, Ferguson AV (2002) Orexin actions in hypothalamic paraventricular nucleus: physiological consequences and cellular correlates. Regul Pept 104:97-103.
Shirasaka T, Nakazato M, Matsukura S, Takasaki M, Kannan H (1999) Sympathetic and cardiovascular actions of orexins in conscious rats. Am J Physiol 277:R1780-R1785.

Siegel JM (1999) Narcolepsy: a key role for hypocretins (orexins). Cell 98:409-412.

Smith BN, Dou P, Barber WD, Dudek FE (1998) Vagally evoked synaptic currents in the immature rat nucleus tractus solitarii in an intact in vitro preparation. J Physiol (Lond) 512:149-162.

Smith BN, Banfield BW, Smeraski CA, Wilcox CL, Dudek FE, Enquist LW, Pickard GE (2000) Pseudorabies virus expressing enhanced green fluorescent protein: a tool for in vitro electrophysiological analysis of transsynaptically labeled neurons in identified central nervous system circuits. Proc Natl Acad Sci USA 97:9264-9269.

Smith BN, Davis SF, van den Pol A, Xu W (2002) Selective enhancement of excitatory synaptic activity in the rat nucleus tractus solitarius by hypocretin 2. Neuroscience 115:707-714.

Sutcliffe JG, de Lecea L (2002) The hypocretins: setting the arousal threshold. Nat Rev Neurosci 3:339-349.

Takahashi N, Okumura T, Yamada H, Kohgo Y (1999) Stimulation of gastric acid secretion by centrally administered orexin-A in conscious rats. Biochem Biophys Res Commun 254:623-627.

Travagli RA, Gillis RA, Rossiter CD, Vicini S (1991) Glutamate and GABAmediated synaptic currents in neurons of the rat dorsal motor nucleus of the vagus. Am J Physiol 260:G531-G536.

van den Pol AN, Gao XB, Obrietan K, Kilduff TS, Belousov AB (1998) Presynaptic and postsynaptic actions and modulation of neuroendocrine neurons by a new hypothalamic peptide, hypocretin/orexin. J Neurosci 18:7962-971.

van den Pol AN, Ghosh PK, Liu RJ, Li Y, Aghajanian GK, Gao XB (2002) Hypocretin (orexin) enhances neuron activity and cell synchrony in developing mouse GFP-expressing locus coeruleus. J Physiol (Lond) 541:169-185.

Wuarin JP, Dudek FE (2001) Excitatory synaptic input to granule cells increases with time after kainate treatment. J Neurophysiol 85:1067-1077.

Yang B, Ferguson AV (2002) Orexin-A depolarizes dissociated rat area postrema neurons through activation of a nonselective cationic conductance. J Neurosci 22:6303-6308. 